\title{
Multicomponent negative-type photoresist based on Noria analog with 12 ethoxy groups
}

\author{
Nobumitsu Niina ${ }^{1}$, Hiroto Kudo ${ }^{2}$, Ken Maruyama ${ }^{3}$, Toshiyuki Kai ${ }^{3}$, Tsutomu Shimokawa ${ }^{3}$, Hiroaki Oizumi ${ }^{4}$, \\ Toshiro Itani ${ }^{4}$ and Tadatomi Nishikubo ${ }^{2}$ \\ The characteristics of Noria analogs with 12 ethoxy groups and 12 hydroxy groups (Noria-OEt), which were synthesized by the \\ condensation reaction of 3-ethoxyphenol with 1,5-pentanedial, were examined in detail. The solubility of the synthesized Noria-OEt \\ in common organic solvents was better than that of Noria. In addition, Noria-OEt was soluble in $2.38 \mathrm{wt} \%$ tetrametyl ammonium \\ hydroxide (TMAH) aqueous as a developer. The thermal stability and mechanical properties were similar to those of Noria because \\ of the ladder structure and amorphous characteristics, which means that the film-forming properties were confirmed. These \\ characteristics are advantageous for use as a molecular glass photoresist. The patterning properties of the negative-type, alkaline \\ developable, multicomponent photoresist based on Noria-OEt, with polyfunctional benzyl alcohols as a crosslinker and a photoacid \\ generator, were evaluated with an extreme ultraviolet lithography system. This negative-type photoresist with 2,4-dihydroxymethyl- \\ 6-methylphenol as a crosslinker gave a resolution pattern of $35 \mathrm{~nm}$ half-pitch with $10.0 \mathrm{~mJ} \mathrm{~cm}$.
}

Polymer Journal (2011) 43, 407-413; doi:10.1038/pj.2010.146; published online 9 February 2011

Keywords: EB; EUV; noria; negative type; resist

\section{INTRODUCTION}

Lithography is an important key technology for the fabrication of semiconductor devices. In particular, electron beam (EB) and extreme ultraviolet light (EUV, $13.5 \mathrm{~nm}$ ) lithography systems are expected to be the next-generation lithographic technologies. These systems demand high-performance photoresist materials with a high resolution of $<22 \mathrm{~nm}$, a high sensitivity of $<10 \mathrm{~mJ} \mathrm{~cm}^{-2}$, a low line-width roughness of $<1.7 \mathrm{~nm}$ and a low out-gas rate. However, it seems that the trade-off relationship between resolution, sensitivity and line-width roughness is the most serious problem in the development of next-generation photoresists. To overcome the trade-off relationships, molecular glasses have received much attention as a next-generation resist because of their small particle size and uniform molecular structure. ${ }^{1-4}$ Fujita et al. reported hexaacetate $p$-methylcalix[6] arena as the first negative-type molecular resist with $\sim 10 \mathrm{~nm}$ resolution by point irradiation of EB..$^{5-7}$ Ueda et al. also reported a multicomponent, alkaline developable, negative-type photoresist composed of calixresorcin[4]arene, with 4,4'-methylenebis[2,6-bis(hydroxymethyl)phenol] as a crosslinker and diphenyliodonium 9,10-dimethoxyanthracene-2-sulfonate as a photoacid generator (PAG), and they achieved a $150-\mathrm{nm}$ resolution pattern., 8 Thereafter, many negative- or positive-type molecular resist materials have been reported using various molecular glasses. ${ }^{10-14}$
More than 10 years ago, C-4-hydoroxyphenylcalix[4]resorcinarene derivatives containing tert-butyl groups $\left(\mathrm{CRA}_{\mathrm{ph}}-\mathrm{COO}^{t} \mathrm{Bu}\right)$ were investigated as positive-type alkaline developable molecular resists. However, a half-pitch (hp) resolution pattern of $<100 \mathrm{~nm}$ was not achieved because CRAph derivatives do not have as much mechanical strength as a positive-type molecular resist under lithographic process conditions.

Therefore, a ladder-type cyclic oligomer was designed with a more rigid structure than that of calixarenes, and the targeted product was synthesized by the condensation reaction of resorcinol with 1,5-pentanedial in $85 \%$ yield. ${ }^{15}$ The resulting product has the expected rigid structure: 24 hydroxy groups, 6 cavities on the side and a large hydrophobic hole through the center of the molecule. Because the structure of the resulting product is similar to that of a water wheel, we named it 'Noria', which means water wheel in Latin.

More recently, various Noria derivatives with the appropriate functional groups have been synthesized and evaluated as positiveand negative-type photoresist materials with chemically amplified systems. ${ }^{16,17}$ A Noria derivative with adamantane groups (Noria-Ad) showed resolution patterns of $26-\mathrm{nm} \mathrm{hp}$, with a dose of $14.5 \mathrm{~mJ} \mathrm{~cm}^{-2}$ as a positively working EUV resist. ${ }^{18,19}$ A Noria derivative with oxcetanyl groups (Noria-GOx) was also synthesized as a negatively working photoresist using the cationic polymerization of oxcetane. ${ }^{20}$

\footnotetext{
${ }^{1}$ Science Frontier, Department of Applied Chemistry, Graduate School of Engineering, Kanagawa University, Yokohama, Japan; ${ }^{2}$ Department of Material and Life Chemistry, Faculty of Engineering, Kanagawa University, Yokohama, Japan; ${ }^{3}$ Semiconductor Materials Laboratory, Fine Electronic Materials Research Laboratories, JSR Corporation, Mie, Japan and ${ }^{4}$ Semiconductor Leading Edge technologies, Inc. (Selete) Research Department 3, Ibaraki, Japan

Correspondence: Professor T Nishikubo, Department of Material and Life Chemistry, Faculty of Engineering, Kanagawa University, Rokkakubashi, Kanagawa-ku, Yokohama 221-8686, Japan.

E-mail: nishikubot@kanagawa-u.ac.jp

Received 20 August 2010; revised and accepted 22 November 2010; published online 9 February 2011
} 
This negative-type photoresist gave a resolution pattern of 45-nm hp with a dose of $13.5 \mathrm{~mJ} \mathrm{~cm}^{-2}$ by the EUV lithography system. These results indicate that these Noria derivatives are excellent candidates for high-performance molecular photoresists for next-generation lithography systems. However, the data are not sufficient for either the resolution or the sensitivity. In addition, it seems that, although Noria has a ladder structure for good mechanical properties and high thermal stability, the solubility of Noria is not sufficient in common organic solvents.

Therefore, novel Noria analogs with 12 hydroxy groups and 12 ethoxy groups (Noria-OEt) were synthesized, which seems to result in better solubility than Noria in common organic solvents. The condensation reaction of 3-ethoxyphenol with 1,5-pentanedial used trifluoroacetic acid as a catalyst in chloroform in a one-pot process. ${ }^{21}$

In this paper, the characteristics of Noria-OEt, including solubility leading to the production of a resist material and the development of an alkaline developable, negative-type photoresist based on Noria-OEt, with polyfunctional benzyl alcohols as a crosslinker and a PAG, are examined. Alkaline developable, negative-type molecular resists might achieve higher resolution than positive-type molecular resists with a $10 \mathrm{~nm}$ resolution region because of their good mechanical properties that are due to the crosslinking reaction of small-sized molecules.

\section{EXPERIMENTAL PROCEDURE}

\section{Materials}

Propylene glycol methyl ether acetate and 3-ethoxyphenol were purchased from Tokyo Chemical Industry Co., Ltd (Tokyo, Japan). Trifluoroacetic acid was obtained from Wako Chemical industry (Osaka, Japan). 1,5-Pentanedial (50\% aqueous solution) was purchased from Kanto Chemical. Co., Inc. (Tokyo, Japan). Methanol, chloroform and $N, N$-dimethylformamide (DMF) were purchased from Godo Co., Ltd (Tokyo, Japan). The crosslinkers 2,6-dihydroxymethyl-4-methylphenol (2,6-DMMP), 2,4-dihydroxymethyl-6-methylphenol (2,4-DMMP), 6,6'-methylenebis[2-(hydroxymethyl)-4-methylphenol] (6-MHMP) and 4,4'-methylenebis[2-(hydroxymethyl)-6-methylphenol] (4-MHMP) were obtained from Asahi Organic Chemicals Industry Co., Ltd (Miyazaki, Japan), and [5,5'-methylenebis(2-hydroxybenzene-5,3,1-triyl)] tetramethanol (5-MBHT) was obtained from Honshu Chemical Industry Co., Ltd (Tokyo, Japan). Triphenylsulfonium trifrate (TPS-Tf) was donated by JSR Corporation (Mie, Japan) and triphenylsulfonium nonafrate (TPS-Nf) was donated by Selete (Ibaraki, Japan). All chemicals were used without purification.

\section{Measurements}

Fourier-transform infrared spectroscopy was performed with a NICOLET 380 FT-IR (ThermoFisher Scientific Inc., Waltham, MA, USA). The ${ }^{1} \mathrm{H}$ nuclear magnetic resonance spectra were recorded on a JNM-ECA-600 (JEOL Ltd, Tokyo, Japan) by dissolving samples in the corresponding deuterated solvents. matrix-assisted laser desorption ionization time-of-flight mass spectrometry analysis was carried out with an AXIMA-CFR plus (Shimazu Co., Kyoto, Japan) in the positive mode. Thermogravimetric analysis was performed on an EXSTAR
6000 (Seiko Instruments Inc., Chiba, Japan) with the sample in an inert nitrogen atmosphere. Before testing, the samples were dried at $100^{\circ} \mathrm{C}$ for $20 \mathrm{~min}$ under nitrogen and then thermally ramped in thermogravimetric analysis to $600{ }^{\circ} \mathrm{C}$ at a heating rate of $10^{\circ} \mathrm{C} \mathrm{min}^{-1}$. Size-exclusion chromatography (SEC) was performed by HLC-8220 (Tosoh Co., Tokyo, Japan) with a Shodex Asahipak GF-510 HQ (7.5 i.d. $\times 300 \mathrm{~mm})$ and two GF-310 HQ columns $(7.5$ i.d. $\times 300 \mathrm{~mm})$, and the DMF solution containing $20 \mathrm{~mm}$ anhydride $\mathrm{LiBr}$ and $20 \mathrm{~mm} \mathrm{H}_{3} \mathrm{PO}_{4}$ was used as a mobile phase. Film thickness was measured with a DHA-OLX (Mizojiri Optical Co., Ltd, Tokyo, Japan). Powder X-ray diffusion data were collected at room temperature on a MultiFlex (Rigaku Corporation, Tokyo, Japan) using $\mathrm{Cu}$ radiation. EB exposure experiments were performed with a Hitachi HL 800D (Hitachi, Tokyo, Japan) at an acceleration voltage of $50 \mathrm{keV}$. EUV lithography was performed by small-field exposure tool with 0.3 numerical aperture connected to a coater/developer track system, ACT-12, in a chemically controlled environment. The scanning electron microscopy (SEM) images were observed by critical dimension-SEM (CD-SEM, S9380II and S9220, Hitachi).

\section{Synthesis of Noria-OEt}

An aqueous solution of 1,5-pentanedial ( $50 \%$ in water, $4.0 \mathrm{~g}, 20 \mathrm{mmol}$ ) was added to a solution of 3-ethoxyphenol $(11 \mathrm{~g}, 80 \mathrm{mmol})$ and trifluoroacetic acid $(15 \mathrm{~g}, 135 \mathrm{mmol})$ as an acid catalyst in chloroform $(20 \mathrm{ml})$ after stirring in reflux for $48 \mathrm{~h}$ (Scheme 1). The reaction solution was poured into methanol, and the precipitate was collected by filtration and then dried in vacuo at $60^{\circ} \mathrm{C}$ for $24 \mathrm{~h}$. The yield was $5.2 \mathrm{~g}(74 \%)$. Infrared $\left(\mathrm{KBr}, \mathrm{cm}^{-1}\right): 3405(\mathrm{vO}-\mathrm{H}), 2977$ ( $v \mathrm{C}-\mathrm{H}$ aromatic), 2930 and $2861(v \mathrm{C}-\mathrm{H}$ aliphatic), 1619 and $1587(v \mathrm{C}=\mathrm{C}$ aromatic), 1233 and $1101(v \mathrm{Ar}-\mathrm{O}-\mathrm{C}) .{ }^{1} \mathrm{H}$ nuclear magnetic resonance (DMSO- $d_{6}, 600 \mathrm{MHz}$, TMS, p.p.m.) $0.45-3.01$ (m, 79.9H, $-\mathrm{CH}_{2} \mathrm{CH}_{2} \mathrm{CH}_{2}-$ and $\left.-\mathrm{OCH}_{2}-\mathrm{CH}_{3}\right), 3.44-4.08\left(\mathrm{~m}, 23.9 \mathrm{H},-\mathrm{O}-\mathrm{CH}_{2}-\mathrm{CH}_{3}\right), 4.08-4.83(\mathrm{~m}, 23.9 \mathrm{H}$, $>\mathrm{CH}), 5.82-7.65(\mathrm{~m}, 24 \mathrm{H}, \mathrm{arH}), 7.65-9.66 \overline{(\mathrm{m},} 11.3 \mathrm{H}, \mathrm{OH})$. matrix-assisted laser desorption ionization time-of-flight mass spectrometry; $[\mathrm{M}+\mathrm{Na}]^{+}$calcd 2065.0, found 2065.7. $M_{\mathrm{n}}=2106, M_{\mathrm{w}} / M_{\mathrm{n}=1.02}$. The yield was $5.2 \mathrm{~g}(74 \%)$.

\section{Typical example of the acid-catalyzed crosslinking reaction of Noria-OEt with crosslinker}

To examine the behavior of the acid-catalyzed crosslinking reaction of NoriaOEt with 2,6-DMMP, the exposed resist film was analyzed by SEC. The resist sample was prepared by dissolving Noria-OEt (73 wt \%), 2,6-DMMP (18 wt $\%$ ) as a crosslinker, TPS-Tf ( $8 \mathrm{wt} \%$ ) as a PAG and trioctylamine (TOA, $1 \mathrm{wt} \%)$ as a quencher in a propylene glycol methyl ether acetate solution containing $30 \mathrm{wt} \%$ DMF as a cast solvent (total content: $5.0 \mathrm{wt} \%$ ), at room temperature. The thin film that was $\sim 60 \mathrm{~nm}$ in thickness, which was formed by spin-coating the photoresist solution on a silicon wafer, was baked at $110^{\circ} \mathrm{C}$ for $60 \mathrm{~s}$, irradiated with ultraviolet light at $254 \mathrm{~nm}$ and re-baked at $110^{\circ} \mathrm{C}$ for $60 \mathrm{~s}$ (post-exposure bake).

The exposed film was soaked in DMF solution of $1 \mathrm{ml}$. The insoluble and soluble parts of the DMF solution were separated by filtration, and then the soluble part was measured by SEC.

\section{Measurement of the sensitivity curve of the negative-type photoresist}

A resist film with a thickness of $\sim 60 \mathrm{~nm}$ was prepared by spin-coating the resist solution (Noria-OEt/2,6-DMMP/TPS-Tf/TOA=73/18/8/1 wt $\%$, total content;<smiles>CCOc1cccc(O)c1</smiles>

3-Ethoxyphenol
$+$<smiles>O=CCCCC=O</smiles>

1,5-Pentanedial
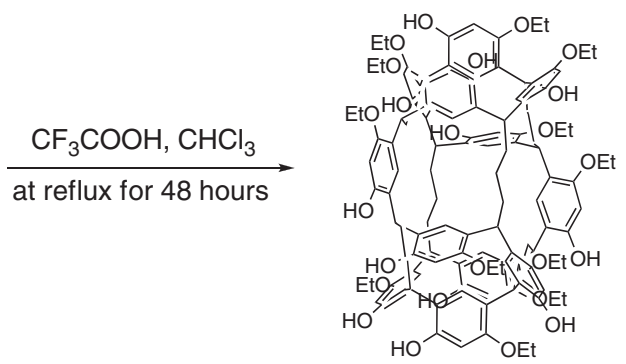

Noria-OEt

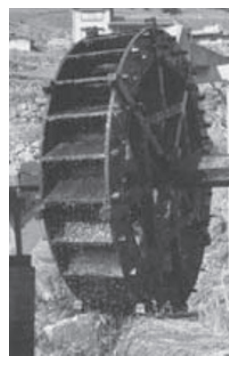

Scheme 1 Synthesis of Noria-OEt by a condensation reaction of 3-ethoxyphenol with 1,5-pentanedial. 
$5.0 \mathrm{wt} \%)$ on a silicon wafer. This film was baked at $110^{\circ} \mathrm{C}$ for $60 \mathrm{~s}$, exposed at $254 \mathrm{~nm}$, re-baked at various temperatures for $60 \mathrm{~s}$ and developed in $2.38 \mathrm{wt} \%$ TMAH aqueous for $60 \mathrm{~s}$. The sensitivity curves were obtained by plotting the change in the normalized film thickness against the exposure dose. The sensitivity of the negative-type photoresist was decided with the dose that left $50 \%$ of film thickness after development.

\section{Evaluation of the patterning properties of the negative-type photoresist}

Evaluation by EB lithography. The resist sample composed of Noria-OEt (73 wt \%), crosslinker (18 wt\%), TPS-Tf ( $8 \mathrm{wt} \%)$ and TOA (1 wt\%) was dissolved in an appropriate cast solvent to yield a $2.5 \mathrm{wt} \%$ solution. This solution was filtered using a $0.45-\mu \mathrm{m}$ membrane filter and spin-coated on a silicon wafer to prepare a thin film with a thickness of $\sim 60 \mathrm{~nm}$. This film was baked at $110^{\circ} \mathrm{C}$ for $60 \mathrm{~s}$, exposed by HL800D at an acceleration voltage of $50 \mathrm{keV}$ and re-baked at $110^{\circ} \mathrm{C}$ for $60 \mathrm{~s}$. The exposed film was developed in $2.38 \mathrm{wt} \%$ TMAH aqueous for $60 \mathrm{~s}$. The resulting patterns were monitored by CD-SEM (S9380II, Hitachi).

Evaluation by EUV lithography system. The resist solution was prepared under similar conditions using TPS-Nf. The film with a thickness of $\sim 60 \mathrm{~nm}$ was formed on a silicon wafer by spin-coating, baked at $110^{\circ} \mathrm{C}$ for $60 \mathrm{~s}$, exposed by small-field exposure tool with a 0.3 numerical aperture and re-baked at $110^{\circ} \mathrm{C}$ for $60 \mathrm{~s}$. The exposed film was developed in $2.38 \mathrm{wt} \%$ TMAH aqueous for $60 \mathrm{~s}$. The resulting patterns were monitored using a CD-SEM (S9220, Hitachi).

\section{RESULTS AND DISCUSSION}

Synthesis and physical properties of Noria-OEt

Noria-OEt was synthesized in good yield by the condensation reaction of 3-ethoxyphenol with 1,5-pentanedial, according to a previous paper. ${ }^{17}$ The structure of Noria-OEt was confirmed by ${ }^{1} \mathrm{H}$ nuclear magnetic resonance, Fourier-transform infrared and matrix-assisted laser desorption ionization time-of-flight mass analysis. The molecular weight $\left(M_{\mathrm{n}}\right)$ and distribution of molecular weight $\left(M_{\mathrm{w}} / M_{\mathrm{n}}\right)$ were estimated by SEC analysis.

Results of the solubility tests for Noria and Noria-OEt are summarized in Table 1. Noria is insoluble in most common organic solvents

\section{Table 1 Solubility test of Noria and Noria-OEt}

\begin{tabular}{lcc}
\hline Solvent & Noria & Noria-OEt \\
\hline Water & - & - \\
DMSO & ++ & ++ \\
DMF & +- & ++ \\
Methanol & - & - \\
2-Propanol & - & +- \\
THF & - & ++ \\
Acetone & - & ++ \\
Ethyl lactate & - & +- \\
Ethyl acetate & - & +- \\
Ethyl ether & - & - \\
Chloroform & - & ++ \\
Anisol & - & ++ \\
PGMEA & +- & ++ \\
$N$-hexane & - & - \\
Diglyme & - & ++ \\
PGMEA & +- & +- \\
2.38 wt\% TMAH & ++ & ++ \\
5.0 wt\% TMAH & ++ & ++ \\
\hline Abbriations: Diglmm & Thy & + \\
\hline
\end{tabular}

Abbreviations: Diglyme, diethyleneglycol dimethyl ether; DMF, dimethylformamide; DMSO, dimethyl sulfoxide; PGME, propylene glycol monomethyl ether; PGMEA, propylene glycol monomethyl ether acetate; Sample/solvent, $1 \mathrm{mg} / \mathrm{ml}$; THF, tetrahydrofuran; ++, soluble at room temperature; + , soluble at heating; +- , partially soluble; - , insoluble. because of the interaction of the 24 hydroxy groups in the molecule. Conversely, Noria-OEt was soluble in many common organic solvents because the number of hydroxy groups in the molecule was less than that of Noria. In addition, Noria-OEt was soluble in $2.38 \mathrm{wt} \% \mathrm{TMAH}$ aqueous

The thermal properties of Noria-OEt were measured by thermogravimetric analysis under nitrogen flow. The thermogravimetric analysis curve was obtained by plotting the weight loss (\%) of Noria-OEt against temperature. As shown in Figure 2, the 5\% weight loss temperature $\left(T_{\mathrm{d}}{ }^{5 \%}\right)$ and $10 \%$ weight loss temperature $\left(T_{\mathrm{d}}{ }^{10 \%}\right)$ were 367 and $376{ }^{\circ} \mathrm{C}$, respectively (Figure 1). This result indicates that Noria-OEt has good thermal stability similar to that of Noria.

The amorphous structure of Noria-OEt was characterized using powder X-ray diffusion. As shown in Figure 2, Noria showed several sharp peaks corresponding to $6^{\circ}, 10^{\circ}, 12^{\circ}$ and $16^{\circ}$. Conversely, Noria-

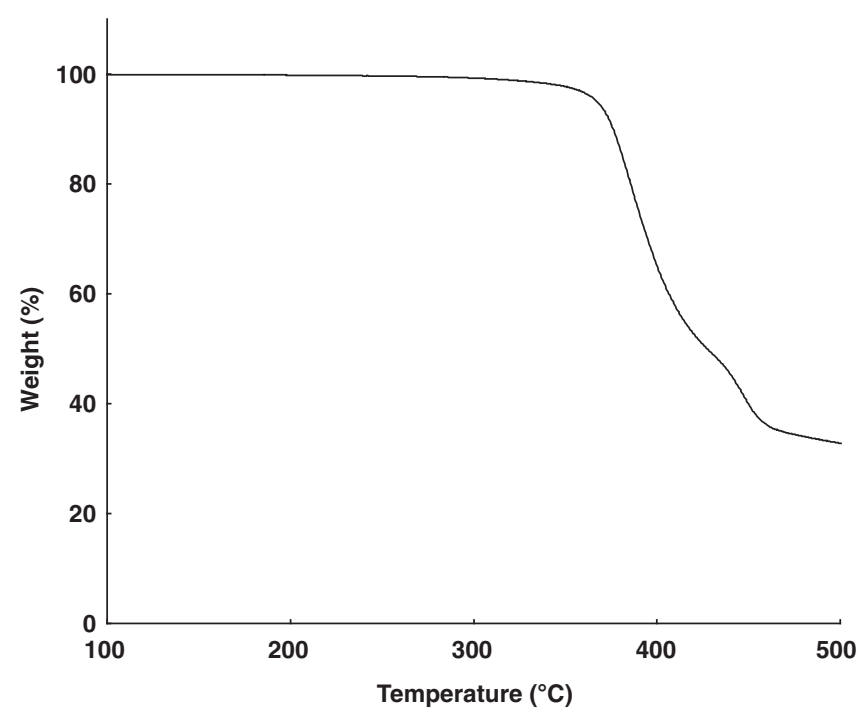

Figure 1 Thermogravimetric analysis of Noria-OEt.

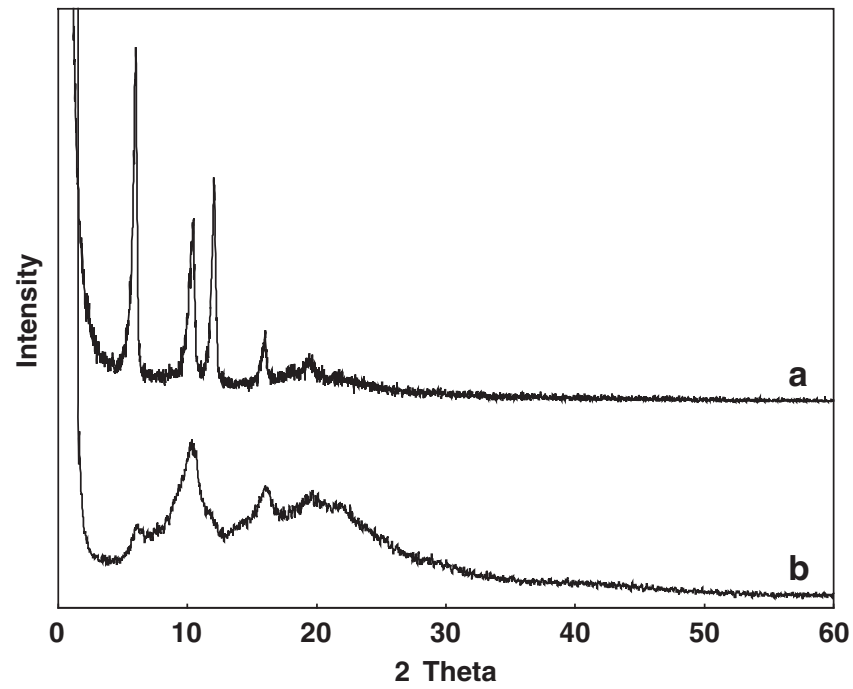

Figure 2 Powder X-ray diffusion patterns of Noria and Noria-OEt recorded at room temperature. (a) Noria, (b) Noria-OEt. 


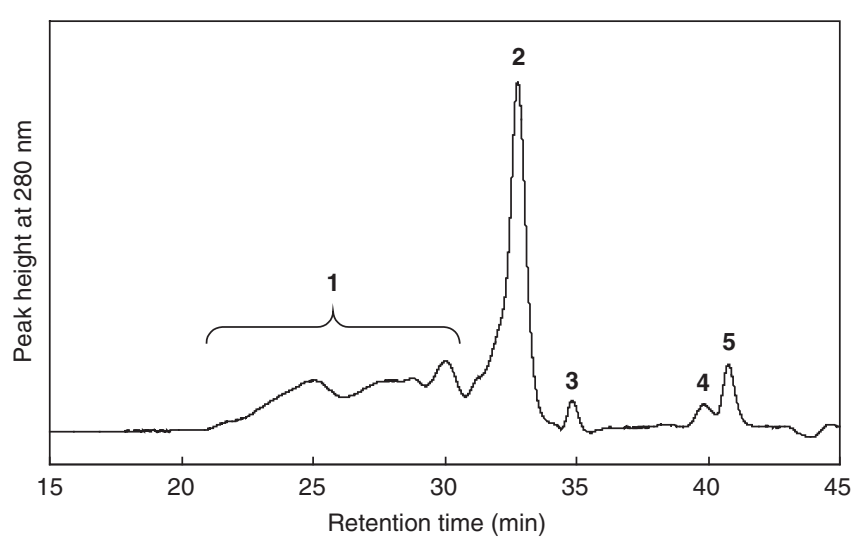

Figure 3 Size-exclusion chromatography profile of the multicomponent, negative-type photoresist after irradiation with ultraviolet light $(254 \mathrm{~nm})$. (1) Crosslinking products of Noria-OEt with 2,6-DMMP, (2) Noria-OEt, (3) photoacid generator, (4) self-condensation product of 2,6-DMMP, (5) 2,6-DMMP.

OEt showed a broad peak around $20^{\circ}$, which indicates amorphous character. The amorphous character is the critical factor leading to the film-forming properties. The resist solution, which was composed of Noria-OEt, crosslinker, PAG and quencher in a propylene glycol methyl ether acetate solution containing $30 \mathrm{wt} \%$ DMF as a cast solvent, was formed easily in a uniform thin film on a silicon wafer by spin-coating.

These data indicate that Noria-OEt can be applied to multicomponent, negative-type, alkaline developable photoresist with chemical amplification.

\section{The acid-catalyzed crosslinking reaction of Noria-OEt with 2,6-DMMP}

The resist film was prepared from resist solution (Noria-OEt/ 2,6-DMMP/TPS-Tf/TOA $=73 / 18 / 8 / 1 \mathrm{wt} \%$, total material content: $5.0 \mathrm{wt} \%)$ on a silicon wafer by spin-coating. This film was exposed to ultraviolet light at $254 \mathrm{~nm}$ and developed in $2.38 \mathrm{wt} \% \mathrm{TMAH}$ aqueous as the developer. The unexposed film was dissolved completely in $2.38 \mathrm{wt} \%$ TMAH aqueous within $60 \mathrm{~s}$. However, the exposed film was stable on the silicon wafer after development.

To examine the acid-catalyzed crosslinking reaction of the resist component from Noria-OEt with the crosslinker, the products and the resist components in the exposed film were analyzed by SEC. The SEC profile is shown in Figure 3. Peaks 2, 3 and 5 correspond to the NoriaOEt, PAG and crosslinker in the resist sample, respectively. The broad peak 1, with a higher molecular weight than that of Noria-OEt, indicates the crosslinking products of Noria-OEt and the crosslinker by the acid-catalyzed reaction. In addition, peak 4 appears to correspond to the dibenzyl ethers because of the self-condensation of the crosslinker by heating. This result suggests that the crosslinking reaction of Noria-OEt with the crosslinker proceeded smoothly with exposure and heating.

The mechanism behind the acid-catalyzed crosslinking reaction of Noria-OEt with crosslinker is proposed in Scheme 2 and is similar to that reported in other papers. ${ }^{8,9,22}$ Benzyl carbocations, which were formed from the crosslinker by acid catalysis, reacted with Noria-OEt to form the crosslinking products. At the same time, benzyl ethers also formed because of the self-condensation reaction of the crosslinker by heating and reaction with Noria-OEt. The acid-catalyzed reaction was faster compared with the thermal reaction because the production rate of the benzyl carbocations was higher than that of benzyl ethers.

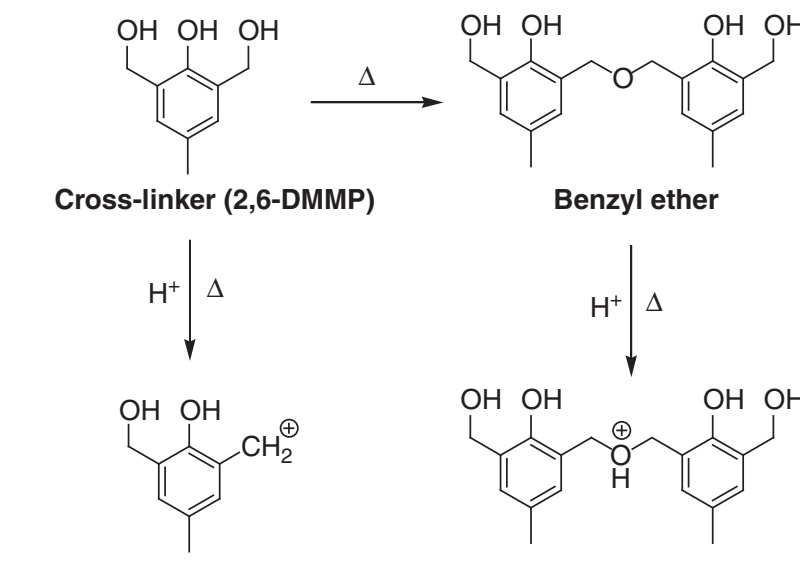

Benzylic carbocation specie

Protonated benzyl ether
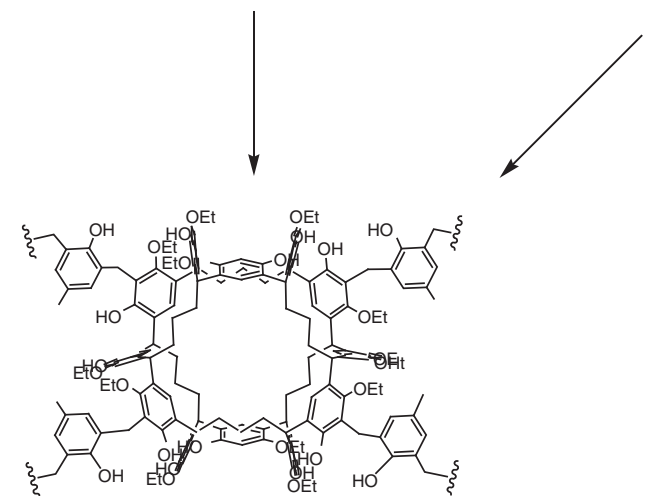

Cross-linking products

Scheme 2 Mechanism of the acid-catalyzed cross-linking reaction of Noria-OEt with cross-linker.

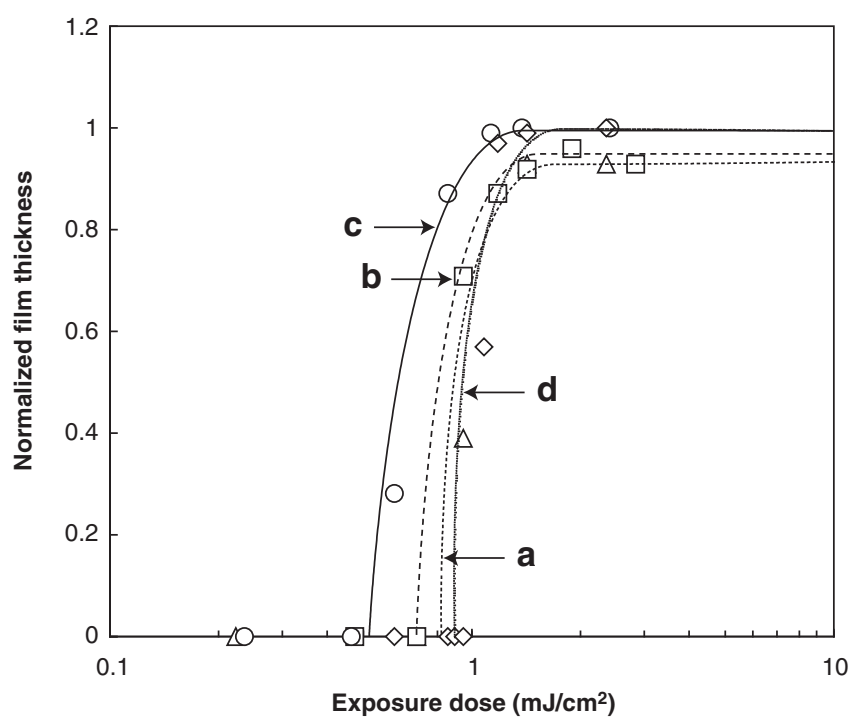

Figure 4 Sensitivity curves of negative-type photoresist composed of NoriaOEt, 2,6-DMMP, photoacid generator and quencher. Post-exposure bake temperature: (a) triangle symbol: $110^{\circ} \mathrm{C}$, (b) box symbol: $120^{\circ} \mathrm{C}$, (c) circle symbol: $130^{\circ} \mathrm{C}$, (d) quarry symbol: $140^{\circ} \mathrm{C}$

The sensitivity curves for this negative-type resist (Noria-OEt/2,6DMMP/TSP-Tf/TOA=73/18/8/1 wt $\%$, total material content: $5.0 \mathrm{wt} \%$ ) in a post-exposure bake temperature range from 110 to $140{ }^{\circ} \mathrm{C}$ are 
Table 2 Contrast and sensitivities at each PEB temperature

\begin{tabular}{lcc}
\hline PEB temperature $(\mathrm{C})$ & Contrast $(\gamma)$ & Sensitivity $\left(\mathrm{mJ} \mathrm{cm}^{-2}\right)$ \\
\hline 110 & 1.4 & 1.0 \\
120 & 2.1 & 0.9 \\
130 & 2.5 & 0.7 \\
140 & 4.3 & 1.0 \\
\hline
\end{tabular}

Abbreviation: PEB, post-exposure bake.<smiles>Cc1cc(CO)c(O)c(CO)c1</smiles>

(1)

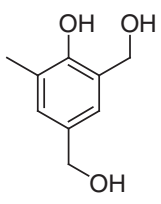

(2)<smiles>Cc1cc(CO)c(O)c(Cc2cc(C)cc(CO)c2O)c1</smiles>

(3)
(4)<smiles>Cc1cc(Cc2cc(C)c(O)c(CO)c2)cc(CO)c1O</smiles><smiles>OCc1cc(Cc2cc(CO)c(O)c(CO)c2)cc(CO)c1O</smiles>

(5)
Figure 5 Structures of polyfunctional benzyl alcohols as crosslinker. (1) 2,6DMMP, (2) 2,4-DMMP, (3) 6-MHMP, (4) 4-MHMP and (5) 5-MBHT.

shown in Figure 4. Values of the sensitivities $\left(\mathrm{D}^{0.5}\right)$ and contrasts $(\gamma)$ are summarized in Table 2. The $\gamma$ value increased with increasing post-exposure bake temperature. Conversely, $\mathrm{D}^{0.5}$ increased from a post-exposure bake temperature of 110 to $130{ }^{\circ} \mathrm{C}$ and decreased at $140^{\circ} \mathrm{C}$

In the high-temperature baking stage, the thermal reaction was accelerated under lower-exposure dosage, that is, the low acid concentration condition. Because benzyl ethers are much less reactive than benzyl carbocations, the production rate of crosslinking products can be slowed down when the concentration of the benzyl ethers in the resist is increased by heating. However, at the high-exposure dosage, the acid-catalyzed crosslinking reaction via benzyl carbocations as an intermediate to form the crosslinking products proceeded more rapidly than the thermal reaction. That is, this resist requires a high-exposure dosage to form the resolution pattern under the high-temperature baking condition (that is, above $140{ }^{\circ} \mathrm{C}$ ).

Lee and Fréchet ${ }^{22}$ also examined the acid-catalyzed crosslinking reaction of poly(4-hydroxystyrene) by polyfunctional benzyl alcohols as a negative-type photoresist and reported the effect of benzyl ethers on the resist sensitivity under various conditions.

\section{Patterning properties of the negative-type photoresist}

The patterning properties of this multicomponent, negative-type photoresist (Noria-OEt/crosslinker/TPS-Tf/TOA $=73 / 18 / 8 / 1 \mathrm{wt} \%$, total material content: $2.5 \mathrm{wt} \%$ ) were evaluated by an EB lithography system. As shown in Figure 5, 2,6-DMMP, 2,4-DMMP, 6-MHMP, 4MHMP and 5-MBHT were used as crosslinkers. Figure 6 shows the SEM images of the resolution patterns with each crosslinker. The 60$\mathrm{nm}$-hp resolution patterns were obtained by the crosslinking reaction with 2,6-DMMP or 2,4-DMMP. In contrast, the photoresist composed of 6-MHMP, 4-MHMP and 5-MBHT only provided a resolution pattern of 70-nm hp. Because the resists are generally prepared on

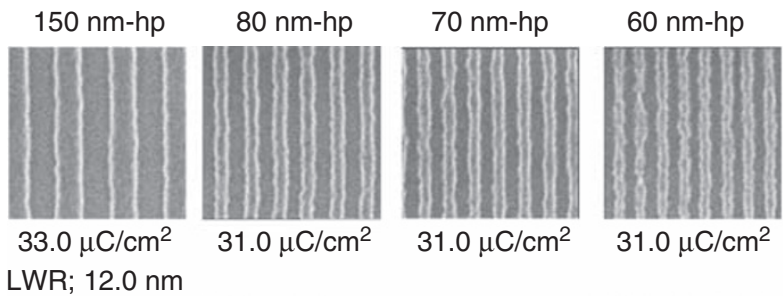

(2)
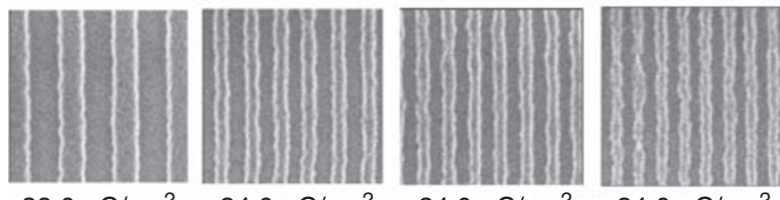

$38.0 \mu \mathrm{C} / \mathrm{cm}^{2}$ LWR; $12.5 \mathrm{~nm}$

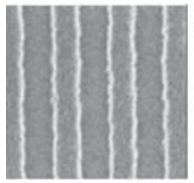

$28.0 \mu \mathrm{C} / \mathrm{cm}^{2}$ LWR; $17.0 \mathrm{~nm}$

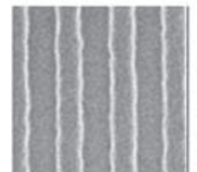

$41.0 \mu \mathrm{C} / \mathrm{cm}^{2}$ LWR; $11.8 \mathrm{~nm}$
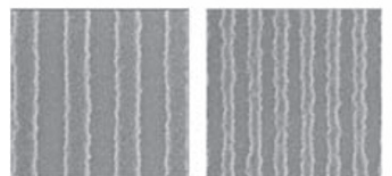

$32.0 \mu \mathrm{C} / \mathrm{cm}^{2}$

$32.0 \mu \mathrm{C} / \mathrm{cm}^{2}$

$34.0 \mu \mathrm{C} / \mathrm{cm}^{2}$

$34.0 \mu \mathrm{C} / \mathrm{cm}^{2}$
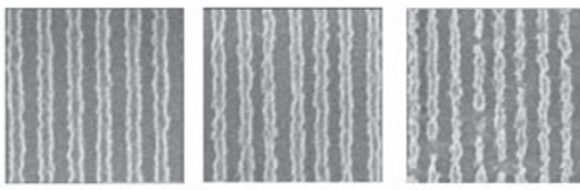

$28.0 \mu \mathrm{C} / \mathrm{cm}^{2}$

$28.0 \mu \mathrm{C} / \mathrm{cm}^{2}$

$28.0 \mu \mathrm{C} / \mathrm{cm}^{2}$
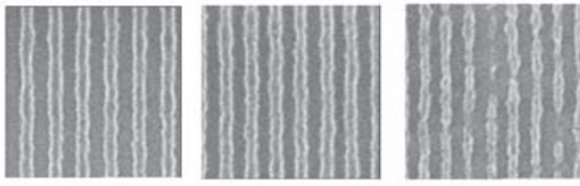

$40.0 \mu \mathrm{C} / \mathrm{cm}^{2}$

$36.0 \mu \mathrm{C} / \mathrm{cm}^{2}$

LWR; $12.0 \mathrm{~nm}$
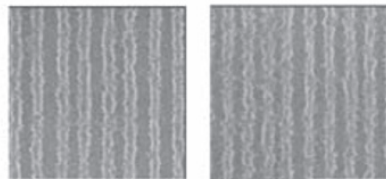

$32.0 \mu \mathrm{C} / \mathrm{cm}^{2} \quad 32.0 \mu \mathrm{C} / \mathrm{cm}^{2}$

Figure 6 SEM images of resolution patterns for the negative-type photoresists by electron beam lithography. (1) 2,6-DMMP, (2) 2,4-DMMP, (3) 6-MHMP, (4) 4-MHMP and (5) 5-MBHT. hp, half-pitch; LWR, line width roughness.

the basis of weight percentage, the molar ratios of 2,6-DMMP or 2,4-DMMP, as the lower molecular weight crosslinkers in the photoresist, were higher than those of 6-MHMP, 4-MHMP or 5-MBHT, which were the higher molecular weight crosslinkers. Therefore, the acid-catalyzed crosslinking reaction of this resist using 2,4-DMMP or 2,6-DMMP proceeded more rapidly than that using 6-MHMP, 4-MHMP and 5-MBHT, and gave a much better resolution pattern. The resolution pattern of this resist using 6-MHMP, 4-MHMP or 5-MBHT can be improved by increasing the molar ratio of the crosslinkers in this resist.

Thereafter, the resist samples using 2,4-DMMP and 2,6-DMMP were evaluated with an EUV lithography system. Figure 7 shows SEM images of negatively working resolution patterns obtained with the EUV lithography system. The resist sample with 2,6-DMMP provided a $40-\mathrm{nm}$-hp resolution pattern with $9.0 \mathrm{~mJ} \mathrm{~cm}{ }^{-2}$. However, the resist sample with 2,4-DMMP provided a 35-nm-hp resolution pattern with $10.0 \mathrm{~mJ} \mathrm{~cm}^{-2}$. Thus, the multicomponent resist films prepared from Noria-OEt with 2,4-DMMP or 2,6-DMMP achieved the targeted sensitivity, although the resolution was not sufficient at this stage. 


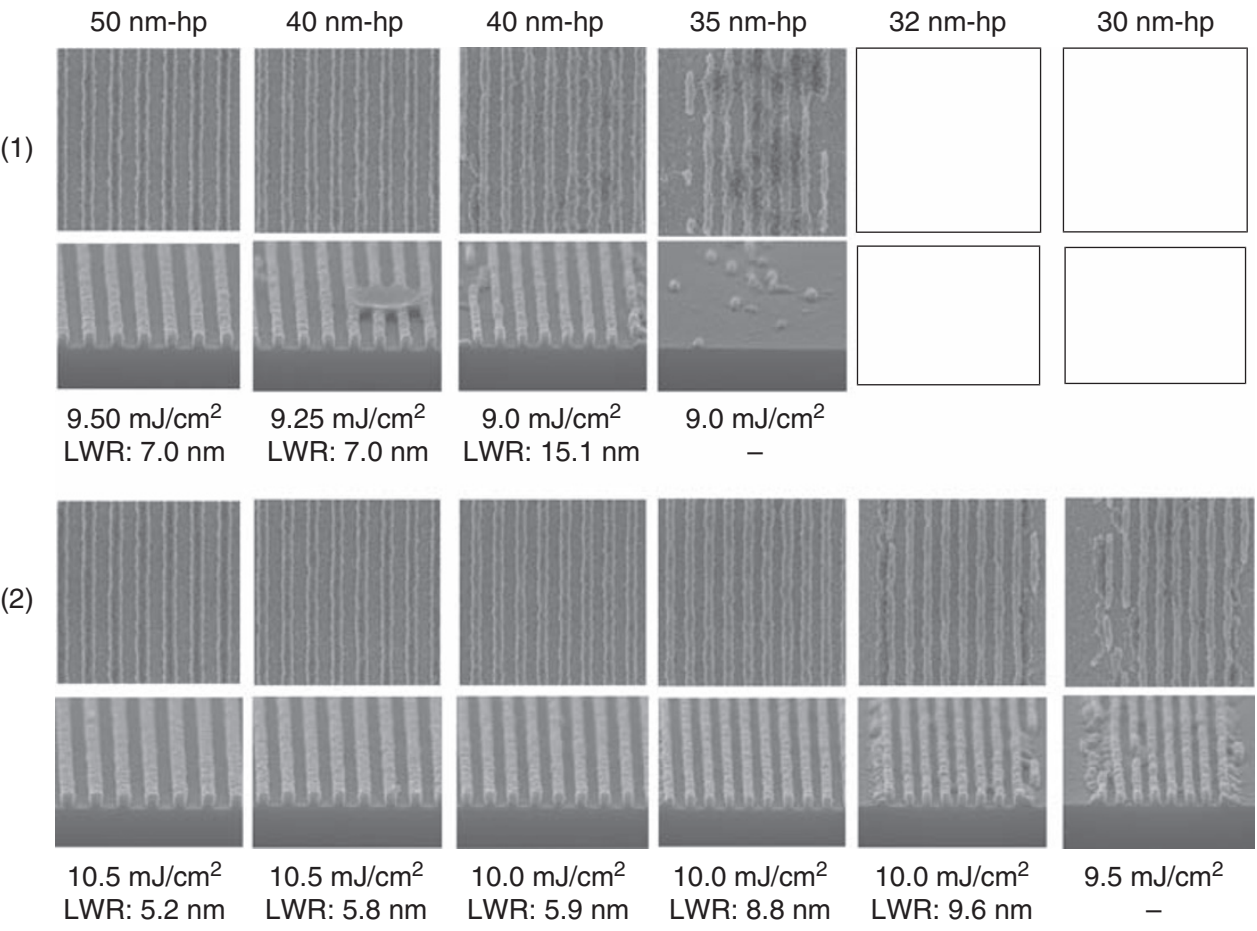

Figure 7 Scanning electron microscopy images of resolution patterns for the negative-type photoresists by extreme ultraviolet lithography. (1) 2,6-DMMP and (2) 2,4-DMMP. hp, half-pitch.

Furthermore, the difference in the resolution of 2,4-DMMP and 2,6DMMP may be explained by their reactivity. The 4-hydroxymethyl groups in 2,4-DMMP were more reactive than the 2-hydroxymethyl groups in 2,6-DMMP, according to a previous paper. ${ }^{23}$ Therefore, the crosslinking reaction of Noria-OEt with 2,4-DMMP proceeded more smoothly than that with 2,6-DMMP and quickly formed the resolution pattern during the lithography process.

\section{CONCLUSION}

In this paper, the characteristics of Noria-OEt were examined, including its solubility in organic solvents. The solubility of the synthesized Noria-OEt in common organic solvents was better than that of Noria. In addition, Noria-OEt was soluble in $2.38 \mathrm{wt} \% \mathrm{TMAH}$ aqueous as a developer. The thermal stability and mechanical properties were similar to those of Noria because of its ladder structure and amorphous character. Thus, its film-forming property was confirmed. These characteristics support its use as a molecular glass photoresist.

Noria-OEt was successfully applied to a multicomponent, negativetype, alkaline developable photoresist that was chemically amplified. This negative-type photoresist, which was prepared by dissolving Noria-OEt (73 wt \%), 2,4-DMMP (18wt\%) as a crosslinker, TPS-Nf $(8 \mathrm{wt} \%)$ as a PAG and TOA $(1 \mathrm{wt} \%)$ as a quencher into propylene glycol methyl ether acetate solution containing $30 \mathrm{wt} \%$ DMF, gave a resolution pattern of $35-\mathrm{nm} \mathrm{hp}$ with $10.0 \mathrm{~mJ} \mathrm{~cm}^{-2}$, using an EUV lithography system.

This multicomponent, negative-type, alkaline developable photoresist might provide a resolution pattern of $<10 \mathrm{~nm}$ with an appropriate crosslinker and lithographic conditions.

\section{ACKNOWLEDGEMENTS}

This work was supported by a Scientific Frontier Research Project from the Ministry of Education, Culture, Sports, Science and Technology, Japan.
1 Silva, A. D., Sundberg, L. K., Ito, H., Sooriyakumaran, R., Allen, R. D. \& Ober, C. K. A fundamental study on dissolution behavior of high-resolution molecular glass photoresists. Chem. Mater. 20, 7292-7300 (2008).

2 Silva, A. D., Lee, J.- K., André, X., Felix, N. M., Cao, H. B., Deng, H. \& Ober, C. K. Study of the structureproperties relationship of phenolic molecular glass resists for next generation photolithography. Chem. Mater. 20, 1606-1613 (2008).

3 Hirayama, T., Shiono, D., Onodera, J., Yamaguchi, A. \& Fukuda, H. Depth profile and line-edge roughness of partially 0 -1-ethoxyethylated low molecular weight amorphous polyphenol and poly( $p$-hydroxystyrene) base resists for electron-beam lithography. Polym. Adv. Technol. 17, 116-121 (2006).

4 Yoshiiwa, M., Kageyama, H., Shirota, Y., Wakaya, F., Gamo, K. \& Takai, M. Novel class of low molecular-weight organic resists for nanometer lithography. Appl. Phys. Lett. 69, 2605-2607 (1996).

5 Ochiai, Y., Manako, S., Yamamoto, H., Teshima, T., Fujita, J. \& Nomura, E. Highresolution, high-purity calix[n]arene electron beam resist. J. Photopolym. Sci. Technol. 13, 413-417 (2000)

6 Fujita, J., Ohnishi, Y., Manako, S., Ochiai, Y., Nomura, E., Sakamoto, T. \& Matui, S. Calixarene electron beam resist for nano-lithography. Jpn. J. App. Phys. 36, 7769-7772 (1997).

7 Fujita, J., Ohnishi, Y., Ochiai, Y. \& Matui, S. Ultrahigh resolution of calixarene negative resist in electron beam lithography. Appl. Phys. Lett. 68, 1297-1299 (1996).

8 Ueda, M., Takahashi, D., Nakayama, T. \& Haba, O. Three-component negative-type photoresist based on calix[4]resorcinarene, a cross-linker, and a photoacid generator. Chem. Mater. 10, 2230-2234 (1998).

9 Nakayama, T., Haga, K., Haba, O.\& Ueda, M. A negative-working alkaline developable photoresist based on calix[4]resorcinarene, a cross-linker, and a photoacid generator. Chem. Lett. 26, 265-266 (1997).

10 Hattori, S., Yamada, A., Saito, S., Asakawa, K., Koshiba, T. \& Nakasugi, T. High resolution positive-working molecular resist derived from truxene. J. Photopoly. Sci. Technol. 22, 609-614 (2009).

11 Chang, S. W., Ayothi, R., Bratton, D., Yang, D., Felix, N., Cao, H. B., Deng, H. \& Ober, C. K. Sub-50 nm feature size using positive tone molecular glass resists for EUV lithography. J. Matter. Chem. 16, 1470-1474 (2006).

12 Tully, D. C., Trimble, A. R. \& Frechet, J. M. J. Dendrimers with thermally labile end groups: an alternative approach to chemistry. Adv. Mater. 12, 1118-1122 (2000).

13 Tada, T. \& Nakayama, T. Nanolithograhpy using fullerene films. Jpn. J. Appl. Phys. 35, 63-65 (1996).

14 Yoshiiwa, M., Kageyama, H., Wakaya, F., Takai, M., Gamo, K. \& Shirota, Y. 1,3,5-Tris [4-(tert-Butoxycarbonylmethoxy)-phenyl]benzene as a novel electron-beam positive resist for nanometer lithography. J. Photopolym. Sci. Tech. 9, 57-58 (1996). 
15 Kudo, H., Hayashi, R., Mitani, K., Yokozawa, T., Kasuga, N. C. \& Nishikubo, T. Molecular Waterwheel (Noria) from a simple condensation of resorcinol and an alkanedial. Angew. Chem. Int. Ed. 45, 7948-7952 (2006).

16 André, X., Lee, J. K., DeSilva, A., Ober, C. K., Cao, H. B., Deng, H., Kudo, H., Watanabe, D. \& Nishikubo, T. Phenolic molecular glasses as resists for next generation lithography. SPIE 6519, 65194B (2007).

17 Kudo, H., Watanabe, D., Nishikubo, T., Maruyama, K., Shimizu, D., Kai, T., Shimokawa, T. \& Ober, C. K. A novel Noria (Water-wheel-like cyclic oligomer) derivative as a chemically amplified electron-beam resist material. J. Mater. Chem. 18, 3588-3592 (2008).

18 Nishikubo, T., Kudo, H., Suyama, Y., Oizumi, H. \& Itani, T. Novel Noria (water wheel-like cyclic oligomer) derivative as a chemically amplified extreme ultraviolet (EUV)-resist material. J. Photopolym. Sci. Technol. 22, 73-76 (2009).
19 Kudo, H., Suyama, Y., Oizumi, H., Itani, T. \& Nishikubo, T. Novel extreme ultraviolet (EUV)-resist material based on noria (water wheel-like cyclic oligomer). J. Mater. Chem. 20, 4445-4450 (2010).

20 Seki, H., Kato, Y., Kudo, H., Oizumi, H., Itani, T. \& Nishikubo, T. Negative-type extreme ultraviolet resist materials based on water-wheel-like cyclic oligomer (Noria). Jpn. J. Appl. Phys. 49, 06GF06 (2010).

21 Niina, N., Kudo, H. \& Nishikubo, T. Synthesis of noria-like macrocycles containing alkoxy groups based on a dynamic covalent chemistry (DCC) system by the $A_{2}+B_{4}$ condensation. Chem. Lett. 38, 1198-1199 (2009).

22 Lee, S. M. \& Fréchet, J. M. J. Mechanism of the acid-catalyzed cross-linking of poly(4hydroxystyrene) by polyfunctional benzyl alcohols: a model study. Macromolecules 27, 5160-5166 (1994).

23 Posse, A. J. \& Belter, R. K. Vitamin C in organic synthesis: reaction with p-hydroxybenzyl alcohol derivatives. J. Org.Chem. 53, 1535-1540 (1988). 